\title{
Estimating the higher heating value of forest and agricultural biomass
}

\author{
Krzysztof Górnicki ${ }^{1, *}$, Agnieszka Kaleta, and Radosław Winiczenko \\ ${ }^{1}$ Department of Fundamental Engineering, Faculty of Production Engineering, Warsaw University of \\ Life Sciences, Nowoursynowska 164, 02-787 Warszawa, Poland
}

\begin{abstract}
The objectives of study were to investigate the ash content, carbon content and the higher heating value and modelling of HHV of forest and agricultural biomass. Five types of biomass were used for the experiments: sunflower husk pellets, wood pellets, straw and hay briquettes, and forest chips. The investigated biomass properties (their average values) change: for ash content between $1.3 \%$ (woods pellets) and $7.3 \%$ (hay briquettes), for carbon content between $37.4 \%$ (forest chips) and $52.0 \%$ (wood pellets), for HHV between $14.8 \mathrm{~kJ} / \mathrm{kg}$ (forest chips) and $20.1 \mathrm{~kJ} / \mathrm{kg}$ (sunflower husk pellets). Two mathematical models from literature and model proposed by the authors were used to the HHV calculation. The model proposed by the authors gave the best results in determination of sunflower husk pellets HHV.
\end{abstract}

\section{Introduction}

One of the most important global problem nowadays is the worldwide energy crisis connected not only with decreasing fossil fuel resources but with global climate changes as well $[1,2]$. Therefore researches are searching for such sources of alternative energy that are cheap, abundant, technologically feasible, and have low influence on environment [3]. Biomass is one of discussed energy sources. All biologically produced matter such as forest and agricultural residues, energy crops and wood is described by term of biomass $[4,5]$. Biomass in contract to fossil fuels, can be regarded as $\mathrm{CO}_{2}$ - neutral fuel, because it absorbs almost the same amount of $\mathrm{CO}_{2}$ from atmosphere during photosynthesis as it releases when used as a fuel. For these reason, biomass is energy source that reduces greenhouse gases $[3,6]$.

The design and operation of biomass combustion systems depend on such biomass characteristics as chemical composition, moisture content, ash amounts, and heating value $[7,8]$. Heating values of biomass, especially its higher heating value (HHV), belongs to the most important parameters that describes the fuel quality [9]. The HHV of a fuel evaluates the amount of heat released during combustion with the original and generated water that is in a condensed state. The higher HHV of fuel the higher its energy output [10].

\footnotetext{
*Corresponding author: krzysztof_gornicki@sggw.pl
} 
There are several methods of estimating of the biomass fuels HHV. This parameter can be experimentally evaluated applying an adiabatic oxygen bomb calorimeter and measuring the changes between the enthalpy of reactants and products [7]. Nowadays, however, various correlations for predicting the values of HHV become more and more popular. These models give relationship between the biomass HHV and the proximate analysis results (contents of moisture, volatile matter, fixed carbon, ash, and sulfur) or ultimate analysis (contents of C, H, O, N, S elements ) or results of both analysis respectively [11]. Ultimate analysis based models for HHV predicting were applied among others by Setyawati et al. [12] for tropical peat and by Ozyuguran et al. [9] for fruit juice pulps and fruit, vegetables and nut residues, stalk, stems etc. As far as proximate analysis based correlations are concerned Cordero et al. [13] used it for HHV prediction of lignocellulosic and carbonaceous materials, whereas Özyuğuran and Yaman [3] applied it for different biomass sub-classes. Hybrid analysis based models were used mainly for coal HHV estimation [14]. Higher heating value was estimated also applying artificial neural network $[2]$.

The objectives of this study were to investigate the ash content, carbon content and the higher heating value and modelling of HHV of forest and agricultural biomass.

\section{Material and methods}

Five types of biomass were used for the experiments: sunflower husk pellets, wood pellets, straw and hay briquettes, and forest chips.

The combustion was conducted in a calorimetric bomb placed in calorimeter LECO AC 600. Evaluation of the HHV was performed in accordance with the standard PN-ISO 1928.2002. The ash and carbon contents were determined using analyzers LECO TGA 701 and LECO $628 \mathrm{CHN}$, respectively.

HHV was modelled using the formulas taken from literature:

$$
\begin{aligned}
& \mathrm{HHV}=x_{1}+x_{2} \mathrm{C} \\
& \mathrm{HHV}=x_{3}+x_{4} \mathrm{~A}
\end{aligned}
$$

and proposed by the authors:

$$
\mathrm{HHV}=x_{5}+x_{6} \mathrm{~A}+x_{7} \mathrm{C}+x_{8}(\mathrm{~A} \cdot \mathrm{C})
$$

where $x_{1}-x_{8}$ are the models constants, $\mathrm{C}$ is the carbon content, wt $\%, \mathrm{~A}$ is the ash content, wt $\%$.

Values of the model (1) constants are shown in Table 1. The constants of the model (2) are as follows [7]: $x_{3}=19.914$ and $x_{4}=-0.2324$. 
Table 1. Constants $x_{1}$ and $x_{2}$ of the model (1).

\begin{tabular}{|c|c|c|c|}
\hline \multirow{2}{*}{ No. } & \multicolumn{2}{|c|}{ Constants of the model (1) } & \multirow{2}{*}{ Reference } \\
\cline { 2 - 4 } & $\boldsymbol{x}_{\mathbf{1}}$ & $\boldsymbol{x}_{\mathbf{2}}$ & \\
\hline $\mathrm{c} 1$ & 1.3178 & 0.3699 & {$[15]$} \\
\hline $\mathrm{c} 2$ & -0.459 & 0.4084 & {$[15]$} \\
\hline $\mathrm{c} 3$ & -1.6701 & 0.4373 & {$[16]$} \\
\hline $\mathrm{c} 4$ & 3.4597 & 0.3259 & {$[7]$} \\
\hline
\end{tabular}

The goodness of fit of the models to the experimental data was evaluated with the root mean square error RMSE:

$$
\mathrm{RMSE}=\sqrt{\frac{1}{n} \sum_{i=1}^{n}\left(y_{p r e}-y_{\exp }\right)^{2}}
$$

where $n$ denotes number of data, $y_{\exp }$ means experimental value and $y_{\text {pre }}$ denotes predicted value.

Significance of the impact of biomass kind on ash content, carbon content and the HHV was determined using ANOVA (after accepting the uniformity test of Lavene's variance). Tukey test HSD was applied for division into uniform groups. Constants of the model (3) $x_{5}-x_{8}$ were found using the regression analyses. Regression analyses and ANOVA $(p<0.05)$ were done using the Statistica 13 software.

\section{Results}

\subsection{Measurements}

Results of the measurements and statistical analysis are presented in Table 2.

The highest average values of ash content contain hay and straw briquettes $(7.3 \%$ and $7.0 \%$, respectively) and the difference is statistically insignificant (Table 2). The discussed values for sunflower husk pellets, forest chips, and wood pellets were the following: $3.0 \%$, $2.1 \%, 1.3 \%$, respectively. The average ash content for sunflower husk pellets differs significantly from described values for wood pellets and forest chips. Obtained values of ash content are slightly different that reported in the literature $[17,18]$.

The average carbon content is the greatest for wood pellets $(52.0 \%)$ (Table 2). Discussed values are significantly different for wood pellets, sunflower husk pellets, straw briquettes, and forest chips $(52.0 \%, 48.4 \%, 40.0 \%, 37.4 \%$, respectively). The $\mathrm{C}$ content of hay briquettes $(38.9 \%)$ does not differ significantly than described content for straw briquettes and forest chips. Obtained values of carbon content are similar for those reported in the literature [17-20]. 
Table 2. The ash and carbon content and the HHV of forest and agricultural biomass and results of statistical analysis.

\begin{tabular}{|c|c|c|c|}
\hline Material & Ash content, wt\% & Carbon content, wt\% & $\mathbf{H H V , ~ k J / k g}$ \\
\hline forest chips & $2.1 \pm 0.7^{\mathrm{a} *}$ & $37.4 \pm 1.6^{\mathrm{a}}$ & $14.8 \pm 0.7^{\mathrm{a}}$ \\
\hline straw briquettes & $7.0 \pm 0.5^{\mathrm{b}}$ & $40.0 \pm 0.7^{\mathrm{b}}$ & $16.0 \pm 0.2^{\mathrm{b}}$ \\
\hline hay briquettes & $7.3 \pm 0.9^{\mathrm{b}}$ & $38.9 \pm 0.5^{\mathrm{ab}}$ & $15.6 \pm 0.3^{\mathrm{ab}}$ \\
\hline wood pellets & $1.3 \pm 0.2^{\mathrm{a}}$ & $52.0 \pm 0.6^{\mathrm{d}}$ & $19.8 \pm 0.2^{\mathrm{c}}$ \\
\hline sunflower husk pellets & $3.0 \pm 0.3^{\mathrm{c}}$ & $48.4 \pm 1.6^{\mathrm{c}}$ & $20.1 \pm 0.6^{\mathrm{c}}$ \\
\hline
\end{tabular}

* the same letters indicated homogenous groups $(\mathrm{p}<0.05)$

The HHV of sunflower husk pellets and woods pellets are almost the same (20.1 and $19.8 \mathrm{MJ} / \mathrm{kg}$, respectively) and this difference is statistically insignificant (Table 2). Discussed values for hay briquettes and straw briquettes are similar $(15.6$ and $16.0 \mathrm{MJ} / \mathrm{kg}$, respectively) and do not differ significantly, moreover the value of HHV for forest chips is the lowest $(14.8 \mathrm{MJ} / \mathrm{kg})$. Similar values of the HHV for biomass can be found in the literature [20-23].

\subsection{Modelling}

Obtained values of the model (3) constants (for all types of considered biomass) are following $(\mathrm{p}<0.0001): x_{5}=4.9422, x_{6}=-2.5170, x_{7}=0.2678, x_{8}=0.0653$ with the RMSE equal 0.384623 .

Results of statistical analysis of the modelling of higher heating value of forest and agricultural biomass are presented in Table 3.

Table 3. RMSE for HHV modelling.

\begin{tabular}{|c|c|c|c|c|c|c|}
\hline \multirow{3}{*}{ Material } & \multicolumn{6}{|c|}{ RMSE } \\
\hline & \multicolumn{4}{|c|}{ Model (1) with constants } & \multirow{2}{*}{ Model (2) } & \multirow{2}{*}{ Model (3) } \\
\hline & c1 & c2 & c3 & c4 & & \\
\hline $\begin{array}{l}\text { sunflower husk } \\
\text { pellets }\end{array}$ & 0.7924 & 0.7368 & 0.5978 & 0.7648 & 1.0128 & 0.4914 \\
\hline wood pellets & 0.7842 & 1.0075 & 1.2973 & 0.6396 & 0.3411 & 0.3570 \\
\hline straw briquettes & 0.1710 & 0.1786 & 0.2265 & 0.5133 & 2.3361 & 0.4755 \\
\hline hay briquettes & 0.2130 & 0.2535 & 0.3204 & 0.5679 & 2.5331 & 0.2761 \\
\hline forest chips & 0.4005 & 0.1658 & 0.1393 & 0.7850 & 3.7732 & 0.3078 \\
\hline
\end{tabular}

Model (3) gives good results (RMSE: $0.28-0.49)$ but it is verified only for considered biomass. This model gives the best results for hay briquettes $(\mathrm{RMSE}=0.28)$ and is suitable for forest chips $(\mathrm{RMSE}=0.31)$. Comparing, however, with other considered models, model 
(3) can be treated as the best for estimation of HHV for sunflower husk pellets $(\mathrm{RMSE}=0.49)$ and as a suitable for wood pellets $(\mathrm{RMSE}=0.36)$.

Model (2) is the best for the determination of the HHV of wood pellets (RMSE=0.34) but for the estimation discussed property for straw briquettes, hay briquettes, and forest chips this model is improper (RMSE $>2)$.

Model (1) can be used for all types of considered biomass ( $\mathrm{RMSE}<1.3$ ). The model includes four sets of constants $x_{1}$ and $x_{2}$ available in the literature (Tab. 1). The best results of HHV modelling gives model (1) with constants c1 (RMSE: 0.17-0.79) and a slightly worse can be considered discussed model with constants c4 (RMSE: 0.51-0.78). Considering four sets of constants it can be accepted that model (1) is the best for forest chips (with constants $\mathrm{c} 3(\mathrm{RMSE}=0.14)$ and $\mathrm{c} 2(\mathrm{RMSE}=0.17)$ ), straw and hay briquettes (coefficients c1 (RMSE: 0.17, 0.21, respectively) and c2 (RMSE: 0.18, 0.25, respectively)).

\section{Conclusions}

1. Model (1) with constants $\mathrm{c} 1$ and model (3) can be used for estimating the higher heating value of all considered forest and agricultural biomass $(0.17<\mathrm{RMSE}<0.79$ and $0.28<\mathrm{RMSE}<0.49$, respectively).

2. Taking into account all considered models it can be stated that:

2.1. Model (1) is the best for HHV calculation of forest chips (model with constants c3), straw and hay briquettes (model with constants $\mathrm{c} 1$ ).

2.2. Model (2) gives the best results for wood pellets HHV calculation (RMSE=0.34).

2.3. Model (3) is the best for the determination of HHV for sunflower husk pellets (RMSE=0.49).

\section{References}

1. C.-Y. Yin, Fuel 90, 1128 (2011)

2. H. Uzun, Z. Yıldiz, J. L. Goldfarb, S. Ceylan, Bioresour. Technol. 234, 122 (2017)

3. A. Özyuğuran, S. Yaman, Energy Procedia 107, 130 (2017)

4. A. Demirbaş, Energy Convers. Manag. 42, 183 (2001)

5. L. Zhang, C. Xu, P. Champagne, Energy Convers. Manag. 51, 969 (2010)

6. G. Mazziotti di Celso, S. Rapagnà, M. Prisciandaro, E. F. Zanoelo, Energy Convers. Manag. 82, 27 (2014)

7. C. Sheng and J. L. T. Azevedo, Biomass Bioenergy 28, 499 (2005)

8. R. Galhano dos Santos, J. M. Bordado, Fuel 212, 431 (2018)

9. A. Ozyuguran, A. Akturk, S. Yaman, Fuel 214, 640 (2018)

10. L. Xu, J. Yuan, Fuel 161, 68 (2015)

11. M. Qi, H. Luo, P. Wei, Z. Fu, Fuel 236, 1400 (2019)

12. W. Setyawati, E. Damanhuri, P. Lestari, K. Dewi, Procedia Eng. 125, 298 (2015)

13. T. Cordero, F. Marquez, J. Rodriguez-Mirasol, J. J. Rodriguez, Fuel 80, 1567 (2001)

14. S. S. Matin, S. C. Chelgani, Fuel 177, 274 (2016)

15. A. Demirbaş, A. H. Demirbaş, Energy Explor. Exploit. 22, 135 (2004)

16. D. A. Tillman, Wood as an Energy Resource (Elsevier, 1978)

17. B. Olanders, B.-M. Steenari, Biomass Bioenergy 8, 105 (1995)

18. W. Zeng, S. Tang, Q. Xiao, J. For. Res. 25, 779 (2014)

19. K. Kubica, M. Ściążko, J. Rańczak, Polityka Energ. 6, 297 (2003)

20. J. W. Wandrasz, A. J. Wandrasz, Paliwa Formowane, Biopaliwa i Paliwa z Odpadów w Procesach Termicznych (Wydawnictwo Seidel Przywecki, 2006) 
21. B. Günther, K. Gebauer, R. Barkowski, M. Rosenthal, C.-T. Bues, Eur. J. Wood Wood Prod. 70, 755 (2012)

22. V. Reva, L. Fonseca, J. L. Lousada, I. Abrantes, D. X. Viegas, Eur. J. For. Res. 131, 1025 (2012)

23. C.-L. So, T. L. Eberhardt, Wood Sci. Technol. 47, 993 (2013) 